\title{
"Умные" системы становятся частью производств наравне с оборудованием
}

Визит на сборочно-монтажное производство

АО «Рязанский Радиозавод"

Ю. Ковалевский

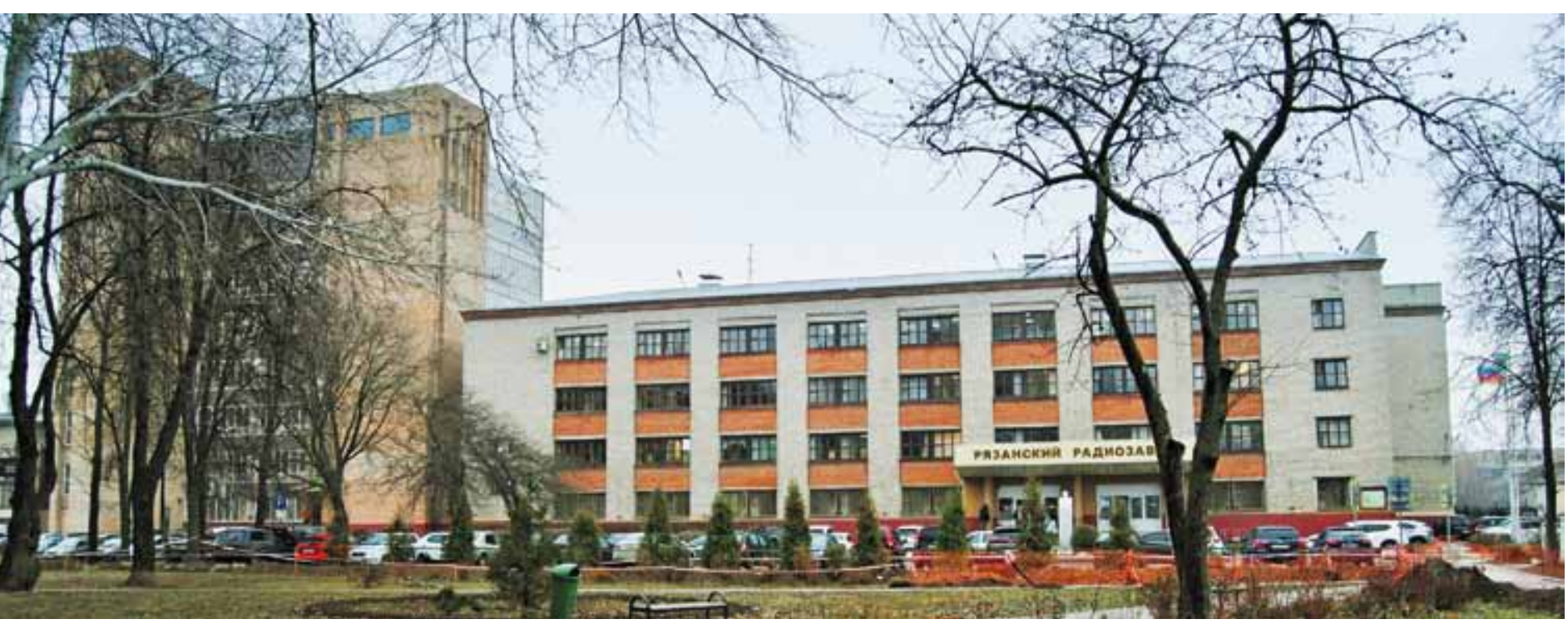

В ноябре прошлого года на площадке АО «Рязанский Радиозавод" проходила конференция, посвященная развитию производственных систем (РПС) и внедрению инструментов "бережливого производства" на предприятиях, входящих в холдинг "Росэлектроника". В опубликованной ранее в нашем журнале статье об этом мероприятии, в частности, говорилось об истории РПС и текущих работах в этой сфере на предприятии. Среди важнейших инструментов повышения эффективности производства - программноаппаратные средства сбора и обработки данных для оптимизации производственных процессов. Недавно на предприятии был внедрен один из таких инструментов - "Умная линия" разработки ООО "ОстекCMT", а к моменту проведения конференции на заводе появилась еще одна система данной компании - "Умное рабочее место", что стало ее первым промышленным внедрением.

Мы посетили подразделение сборки печатных узлов АО «Рязанский Радиозавод", с тем чтобы увидеть, как организованы эти процессы на предприятии, как новые решения помогают в эффективном управлении производством, а также узнать о планах на будущее, направленных на дальнейшее совершенствование процессов и повышение их эффективности. Показал нам производство и ответил на наши вопросы первый заместитель генерального директора - исполнительный директор АО «Рязанский Радиозавод" Алексей Сергеевич Широков. 
Алексей Сергеевич, как давно на вашем предприятии существуют автоматизированные линии поверхностного монтажа?

Первая линия поверхностного монтажа у нас на заводе была запущена в 2007 году. Этому предшествовала достаточно серьезная подготовительная работа. Сборка печатных узлов - один из важнейших процессов производства современной электронной аппаратуры. Без преувеличения можно сказать, что функциональность изделия и применяемые в нем инновации в основном сосредоточены именно на уровне электронных сборок. На этапе их изготовления в очень большой степени закладывается и качество конечной продукции. Более того, если раньше устройство можно было отремонтировать с помощью обычного паяльника, то теперь для этого нужны дорогостоящие специализированные станции и достаточно высокая квалификация ремонтника. Поэтому задачи автоматизации и повышения качества именно на этапе монтажа печатных узлов оказываются первостепенными.

Когда мы говорим о таких операциях, как фрезеровка, токарная обработка, штамповка и т. п., то, как выполнять автоматизацию процессов, в общих чертах понятно даже неспециалисту. Допустим, у вас есть несколько фрезерных станков и рабочие, которые выполняют на них соответствующие операции. Вы заменяете это оборудование на станки с ЧПУ. Изделия теперь обрабатываются по программе, а обслуживание нескольких единиц оборудования может выполняться одним оператором. Конечно, здесь есть определенные тонкости, но в целом задача решается так.

Однако с процессами монтажа компонентов на плату всё не так просто. Еще на этапе выбора оборудования необходимо учитывать не только целый ряд различных параметров, но и то, насколько его характеристики будут отвечать потребностям будущего.
Каждому предприятию хотелось бы сразу построить идеальное производство. Но все мы работаем в условиях ограниченных ресурсов, поэтому приходится действовать поэтапно, и на каждом шаге нужно, с одной стороны, обеспечить выполнение текущих задач, а с другой - иметь четкое представление о дальнейших планax по дооснащению.

Здесь я хотел бы отметить, что нам повезло: более 15 лет назад мы начали сотрудничество с компанией Остек. Я думаю, нам было бы очень тяжело, почти невозможно справиться самим, без той помощи, которую нам оказали специалисты этой компании. Они были очень последовательны в этих вопросах, помогая нам постепенно развивать наше сборочно-монтажное производство. И сейчас, по моему мнению, наше производство поверхностного монтажа вышло на высокий уровень, вполне сравнимый с европейским.

С чего начинался поверхностный монтаж на предприятии и какие возможности есть у него сегодня?

Изначально это была линия, включавшая минимум оборудования: принтер, один автомат установки компонентов и печь оплавления. Затем мы постепенно стали
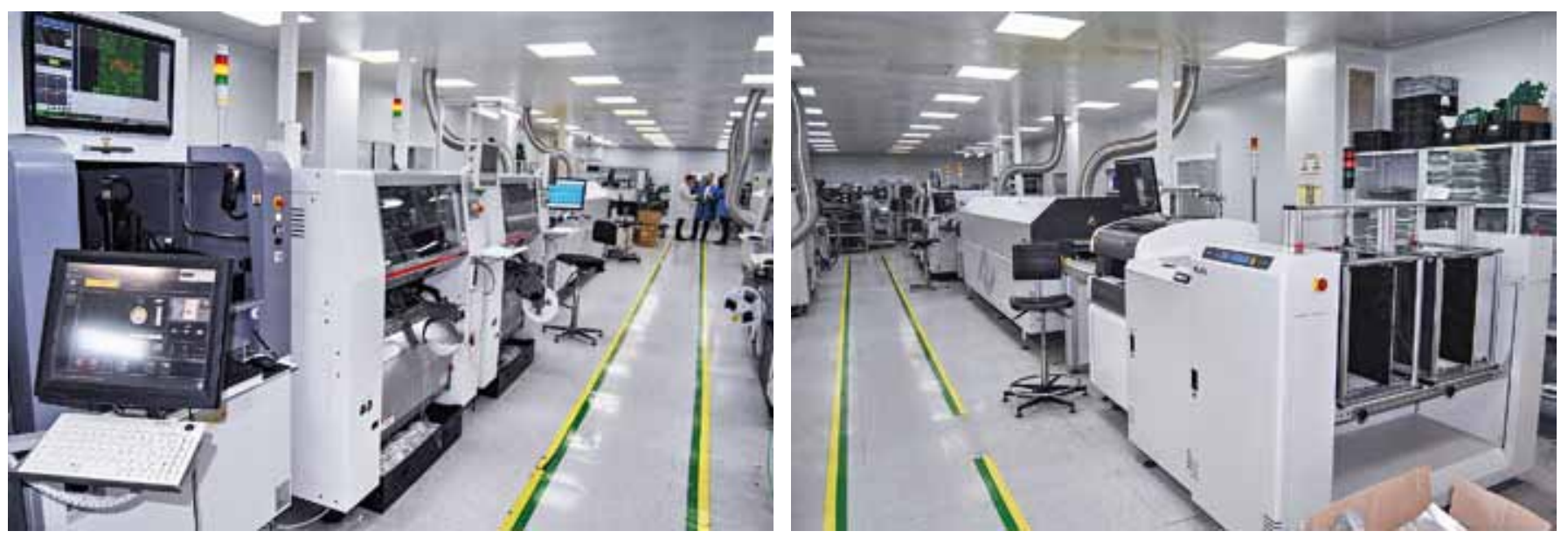

Линии поверхностного монтажа на сборочно-монтажном производстве АО «Рязанский Радиозавод" 


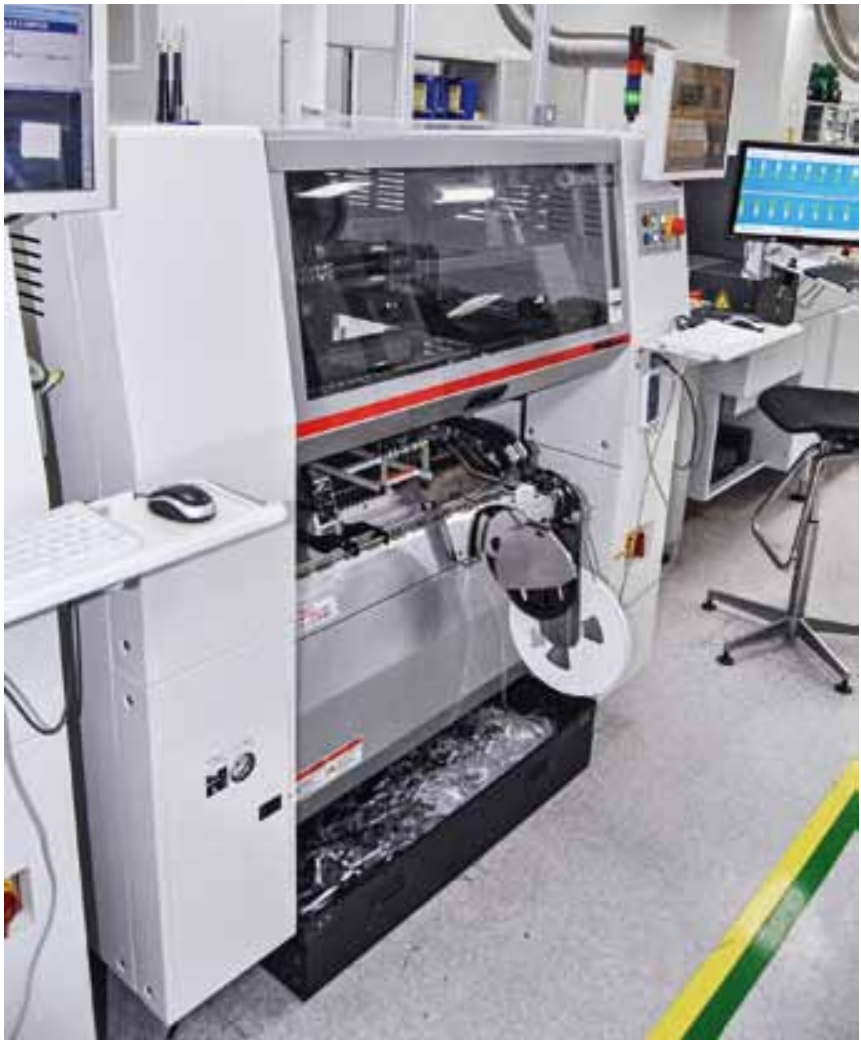

Одно из последних приобретений предприятия - автомат установки компонентов Hanwha SM482 Plus

добавлять установки, расширявшие возможности линии и помогавшие повышать качество продукции. Мы приобрели второй автомат, затем систему автоматической оптической инспекции (АОИ) в конце линии. Позже мы установили еще одну установку оптической инспекции - АИП (SPI) для контроля нанесения паяльной пасты.

В 2011 году мы поставили вторую линию поверхностного монтажа.

На данный момент наше производство позволяет монтировать практически все применяемые в отрасли компоненты, включая чипкомпоненты 01005 и ВGА-корпуса с шагом выводов 0,2 мм. Семизонная печь обеспечивает качественную пайку сложных плат в том числе по бессвинцовой технологии.

\section{Вы уже ставили компоненты 01005 в серии?}

Пока нет. Но компоненты 0201 в большом количестве применяются в изделии, которое с 2020 года будет серийно выпускаться на нашем предприятии. Это реальные изделия, профессиональные DMR-радиостанции гражданского применения разработки Концерна "Созвездие». Это очень интересный проект, который мы считаем для себя перспективным. Он должен вывести нас на новый уровень. Данные устройства практически полностью собираются по технологии поверхностного монтажа и содержат очень сложные с точки зрения сборки компоненты. Сейчас мы уже практически готовы к серийному выпуску этой продукции.

Помимо средств радиосвязи, для каких секторов промышленности вы собираете изделия?

Достаточно большую долю среди изготавливаемой у нас продукции составляют различные устройства управления, сигнализации, охранных систем. Сейчас мы плотно работаем по проекту “Умный дом».

Еще один сектор - системы навигации для автомобильного и железнодорожного транспорта. В частности, изготавливаемые у нас системы "ЭРА-ГЛОНАСС" устанавливаются на автомобили, собираемые в нашей стране.

Пожалуй, это три основных направления, которые мы считаем для себя наиболее перспективными

Все эти направления - гражданские, а в нашей стране уделяется большое внимание развитию гражданской продукции. Как вы оцениваете рынок для российской электроники гражданского применения?

Рынок огромный. Большим потенциалом обладают и региональный, и всероссийский, и зарубежные рынки:

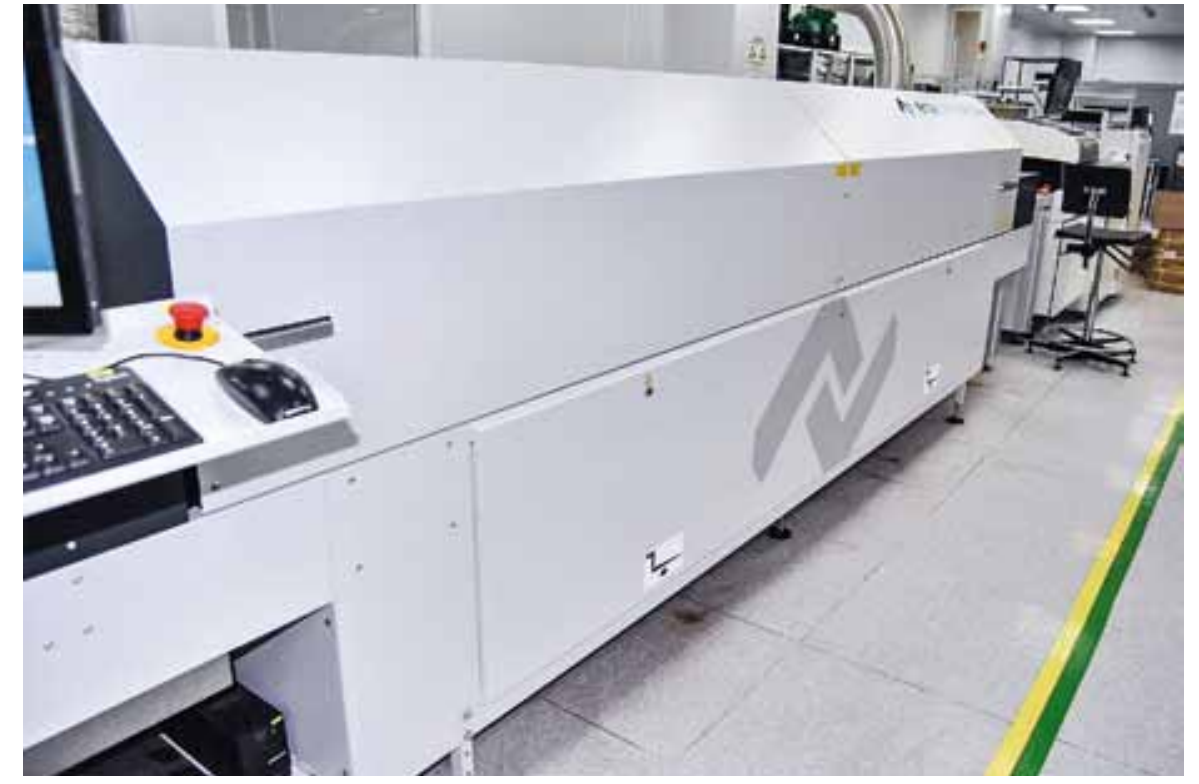

Печь пайки оплавлением Ersa Hotflow 3/14е с семью зонами нагрева и двумя - охлаждения 
Европы, Азии, Латинской Америки, Африки. Главное найти продукт, который будет интересен рынку и конкурентоспособность которого мы сможем обеспечить.

Очевидно, что на сегодняшний день состязаться с передовыми компаниями в области, например, персональных компьютеров общего применения мы не сможем. Но продукты, с которыми мы можем совершенно спокойно конкурировать, безусловно, есть.

Вы упомянули, что DMR-радиостанции - это проект Концерна "Созвездие". Изделия, которые собираются на этой площадке, - это только проекты холдинга "Росэлектроника", или вы также оказываете услуги контрактного производства для внешних заказчиков?

Мы оказываем услуги контрактного производства с 2012 года. Тогда мы только запустили вторую линию, образовались свободные мощности, которые нужно было загрузить как можно быстрее, и мы это делали за счет внешних заказов.

Но сегодня это направление трансформировалось. Это уже не та схема, когда заказчик приезжает к нам, мы подписываем договор, собираем для него изделие, отгружаем, и на этом всё заканчивается. Сейчас наше взаимодействие с заказчиками более правильно называть совместными проектами, а сами заказчики фактически становятся нашими партнерами. Мы уже не только собираем печатные узлы по документации заказчика, мы обеспечиваем ему полный цикл изготовления конечного изделия вплоть до упаковки, а также совместно с ним вносим изменения в конструкции

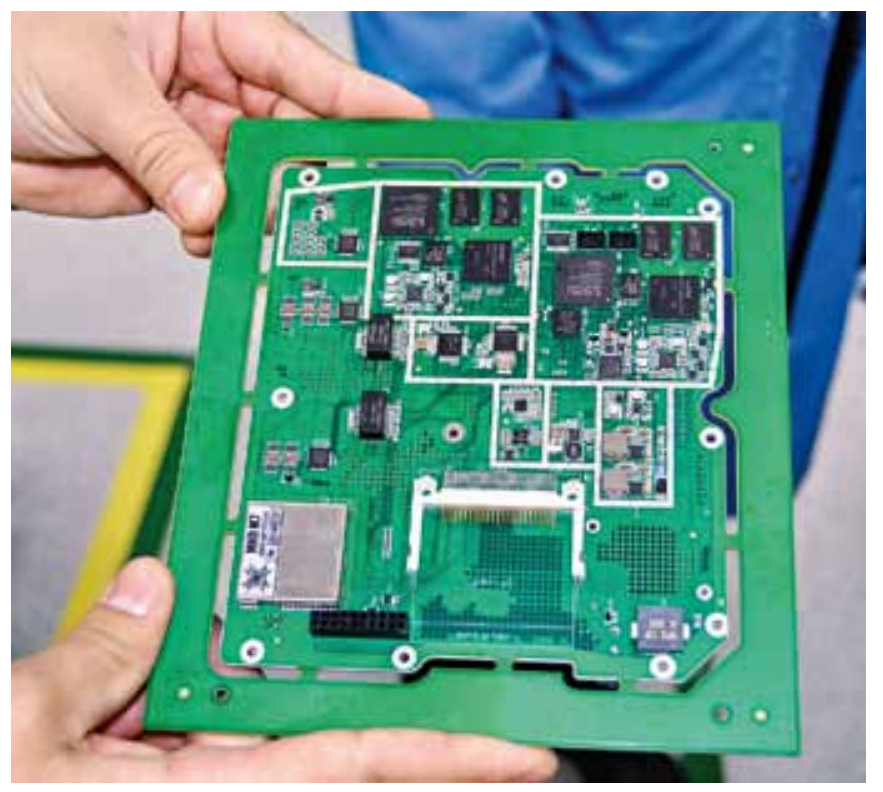

Пример печатного узла, собранного на сборочно-монтажном производстве АО "Рязанский Радиозавод" некоторых изделий для увеличения технологичности. Такие проекты у нас есть, в частности, по автомобильной тематике. Направление "умного дома", о котором я говорил, также относится к такому взаимодействию с компанией, которая разрабатывает эти системы.

Стратегически мы стараемся идти по этому пути, становиться участником проекта как технологический партнер. Но некоторая доля классического контрактного производства у нас есть. Обычно это либо заказы очень малого, практически единичного объема, но с очень высокими требованиями к качеству, либо, наоборот, те случаи, когда заказчику нужно достаточно быстро изготовить крупную партию.

Вы сказали, что после запуска второй линии ее потребовалось дополнительно загружать. Эта линия приобреталась с целью увеличения объемов или были и другие причины?

Конечно, увеличение объемов было одной из главных причин. Но была и другая - дублирование, обеспечение возможности продолжать работу при плановом или внеплановом обслуживании того или иного оборудования. Как говорится, один станок- не станок, два половина станка, и только три - это станок. Пока у нас только две линии, но они полноценные и гибкие. Этого на данный момент достаточно. Но мы всегда думаем о будущем, и я предполагаю, что в определенный момент у нас линий станет больше.

Однако это сейчас не первый приоритет. Повторю: мы движемся вперед поэтапно, оцениваем перспективу, планируем по крайней мере на два года вперед,

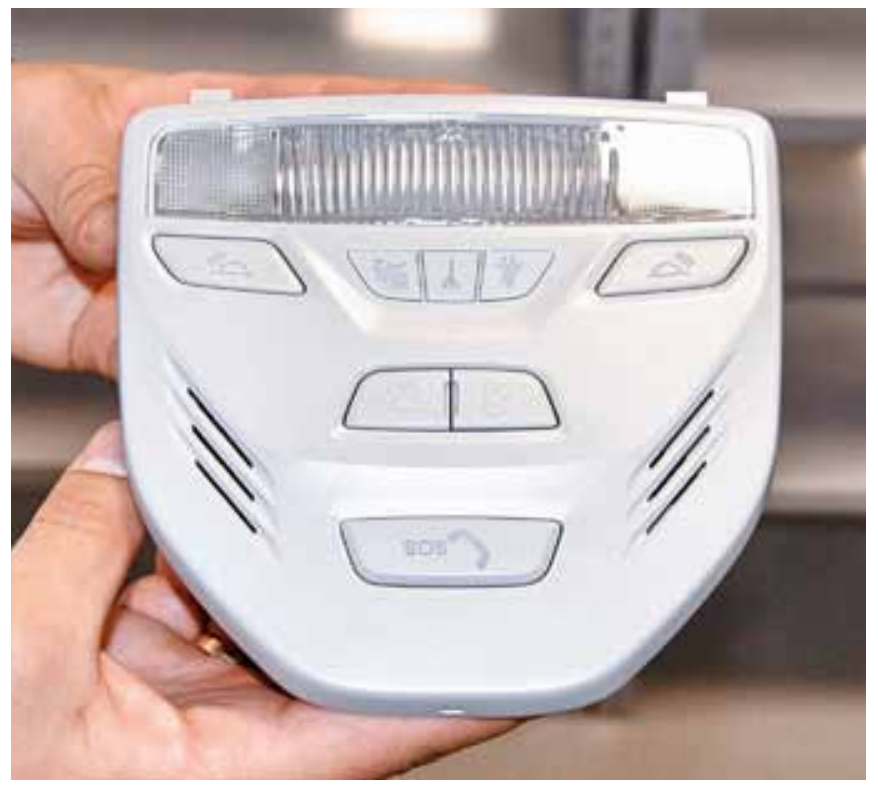

Готовый блок для салона автомобиля с системой экстренного вызова "ЭРА-ГЛОНАСС" 
какое оборудование будем приобретать для расширения производства или замены устаревших установок. А модернизацию производства мы проводим постоянно. Уже нельзя сказать, что у нас работают линии 2007-го и 2011-го года: практически все установки в них в тот или иной момент были заменены на более современные, соответствующие требованиям сегодняшнего дня. С 2011 года осталась, пожалуй, лишь одна система АОИ.

\section{И что сейчас составляет первый приоритет?}

В отношении производственного оборудования у нас есть планы по приобретению второй установки селективной пайки. Первую машину мы установили относительно недавно, очень быстро освоили этот процесс и сейчас уже чувствуем потребность во второй устаHOBKe.

\section{Означает ли это, что доля монтажа в отверстия всё еще остается высокой?}

Смотря как считать. Если по количеству точек пайки, то, безусловно, поверхностный монтаж превосходит монтаж в отверстия во много раз. Он составляет порядка 85-90\%. Но если считать по трудоемкости, то ситуация противоположная. На линияху нас работает всего два оператора в смену - по одному на каждой линии, а численность монтажников - 40 человек.

Тенденция к сокращению доли монтажа в отверстия, однако, сохраняется. Появляется всё больше компонентов, предназначенных для автоматизированного монтажа, в том числе среди тех их типов, которые долгое время существовали только в штыревом варианте, таких как разъемы, индуктивности. А внедрение селективной пайки позволяет еще больше снизить долю ручного монтажа в общей трудоемкости сборки печатных узлов.

\section{Вместе с этим сокращается и потребность в мон-} тажниках?

Да. Но сама профессия всё еще востребована: существуют монтажные операции, которые еще очень сложно автоматизировать, например пайка жгутов или монтаж крупногабаритных моточных изделий.

Как, из вашего опыта, меняется ситуация с отечественной эКБ для автоматизированного монтажа?

Она улучшается. Если раньше были очень серьезные проблемы, прежде всего связанные с упаковкой, то сейчас появляется всё больше российских компонентов для поверхностного монтажа, упакованных в ленту.

Три-четыре года назад мы даже связывались с одним предприятием, которое выпускает транзисторы, и просили их поставлять свои изделия в упаковке, предназначенной для автоматизированного монтажа. Они на тот момент помещали каждый транзистор в индивидуальную фольгированную упаковку. Мы пытались донести до них то, что это не только создает неудобства для сборочного производства и приводит к дополнительным затратам с нашей стороны, потому что мы вынуждены монтировать эти компоненты вручную, но и вызывает удорожание самих изделий: фольга - это весьма недешевая упаковка. Но тогда нам их убедить не удалось. А теперь отечественные компоненты такого типа уже стали доступны в ленте.

Но ситуация еще очень далека от идеала. По всей видимости, это связано с тем, что у нас не такие объемы потребления ЭКБ, чтобы производителям компонентов было выгодно вкладываться в изменение технологии.

Из того, что задача приобретения третьей линии не столь актуальна, можно сделать вывод, что две существующие линии еще обладают запасом производительности, или, иными словами, они недогружены. Это так?

На сегодняшний день, в том числе благодаря новым проектам и услугам контрактного производства, у нас загрузка такова, что этот участок работает круглосуточно. Но мы видим потенциал для еще большего увеличения объема. И это без необходимости закупки дополнительного оборудования.

Относительно недавно мы внедрили систему "Умная линия", которая, в частности, позволяет выполнять расчет такого показателя, как OEE (overall equipment effectiveness - общая эффективность оборудования), для каждой из линий в реальном времени, собирая данные непосредственно с установок. Этот показатель вычисляется, как произведение трех критериев, выражаемых в процентах: доступности, производительности и качества. Критерий доступности отражает потери на остановки. Это отношение операционного времени, то есть времени, в течение которого оборудование работало, к планируемому производственному времени. Критерии производительности и качества - более сложные, они зависят от особенностей конкретного производства. Первый из них показывает, насколько время цикла близко к идеальному, а второй - какая доля изготовленной продукции соответствует требованиям качества. Сейчас мы настраиваем эти два показателя с учетом нашей специфики. Например, поскольку номенклатура выпускаемых изделий большая, а партийность за редким исключением не превышает 200 шт. и, соответственно, комплектация также меняется от запуска к запуску, мы обычно регулируем систему АОИ на выходе линии так, чтобы с большей вероятностью не пропустить дефект, а это приводит к ложным 
срабатываниям. Окончательное решение по дефекту принимает оператор, оценивающий изделия, отбракованные АОИ. Поэтому, если собирать данные непосредственно с оборудования и рассчитывать критерий качества по обычной формуле, без поправок, то он будет, как правило, занижен и будет слабо отражать реальное положение вещей.

Так что здесь еще требуется некоторый объем работ, и мы надеемся, что в скором времени мы этот показатель адаптируем под наше производство.

Однако даже критерии доступности и производительности дают очень полезную информацию. Мы их вычисляли и раньше, но это делалось вручную со всеми вытекающими последствиями: влиянием человеческого фактора, большим объемом рутинной работы и невозможностью отслеживать ситуацию в реальном времени.

Сейчас система "Умная линия» показывает нам, что на первой линии ОЕЕ составляет 13\%, а на второй-26\%. Это данные на текущий момент, и низкие значения связаны с тем, что утром обе линии перезаряжались. В среднем за сутки обычно этот показатель достигает 60-70\%.

Анализируя показатель ОЕЕ, можно выявить, по каким причинам не достигается максимальная эффективность, и оптимизировать работу линии. Сейчас мы можем видеть, что около 30-40\% времени линии простаивают. Конечно, до нуля это значение снизить невозможно, потому что оно включает и плановые простои. Но из нашего анализа общей картины мы можем сделать вывод, что потенциал для дополнительной загрузки этого оборудования еще есть.

\section{Анализ и оптимизация загрузки} производства были основной целью приобретения системы "Умная линия"? Как вообще возникла идея внедрить такую систему?

Система «Умная линия» - это аппаратно-программный комплекс. Она является такой же частью линий, как и производственное или контрольное оборудование, и ее приобретение - это тоже элемент модернизации линий, обновления процессов.

Задумываясь о модернизации, мы всегда смотрим, что появляется в мире нового. Мы посещаем выставки, как российские, так и зарубежные, смотрим, в какую сторону развиваются производства, что предлагают поставщики технологий, и стараемся брать всё лучшее, что есть на сегодняшний день и что отвечает нашим задачам.

Сейчас такое время, что слово "умное» можно встретить на каждом шагу: "умные производства", "умные дома», "умные города»... Наверное, без "умного производства", без самонастраивающихся производственных систем будущего нет, потому что только таким образом можно достичь уровня эффективности, который необходим для изготовления конкурентоспособной продукции.

Однако легко назвать производство "умным», но сделать - очень сложно. В полной мере концепция самоорганизующихся производств, "Индустрии 4.0" еще не реализована нигде. Но элементы этого появляются, и система "Умная линия» - один из таких элементов. Ее внедрение для нас - новый этап развития.

"Умная линия" должна помочь нам добывать правильную, актуальную, релевантную информацию. Без такой информации невозможно качественное управление, а без него, в свою очередь, не получится повысить эффективность производства - увеличить производительность без дополнительных инвестиций в оборудование, что является одной из основных целей, которые мы перед собой ставим в настоящее время.

Современное оборудование поставляется с программным обеспечением (ПО), которое, как правило, позволяет собирать и обрабатывать определенную информацию о техпроцессе. Этого ПО недостаточно

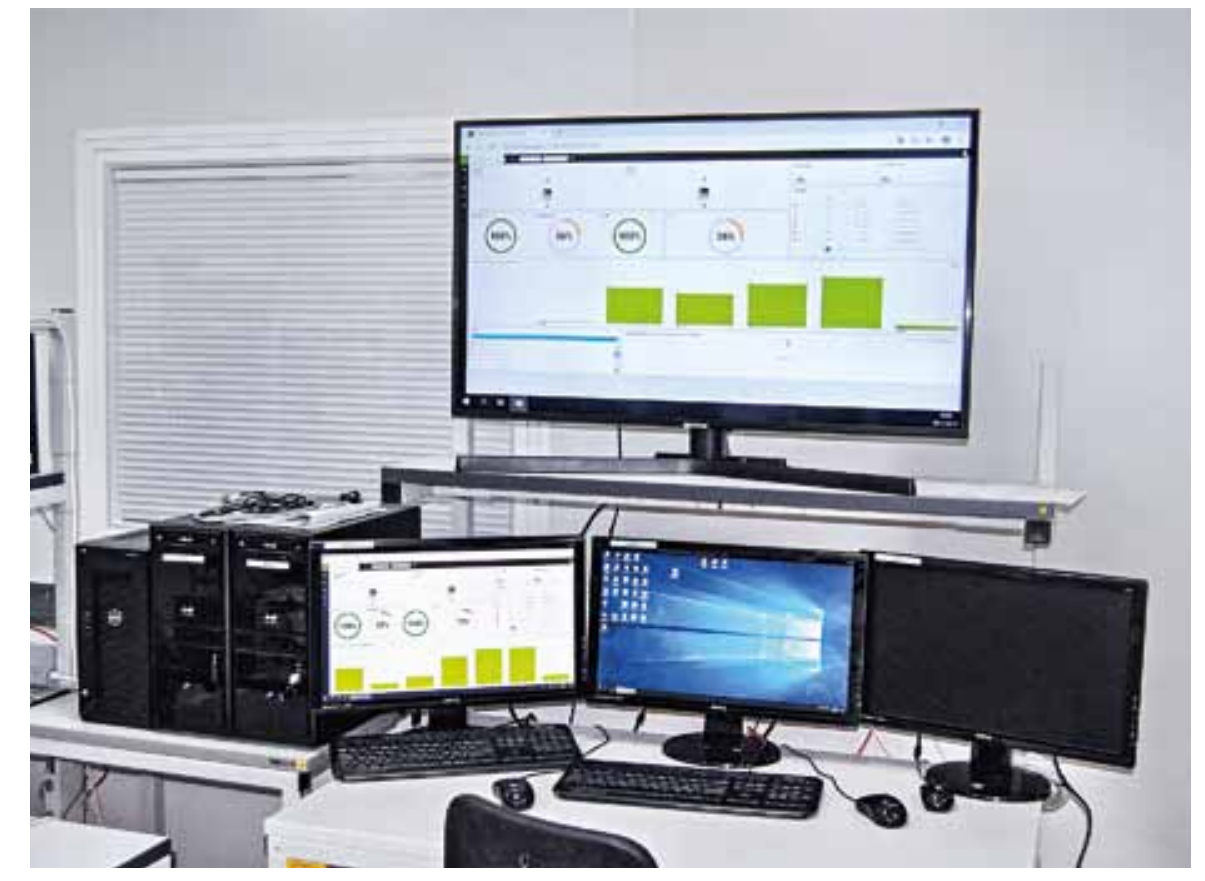

Мониторы системы "Умная линия» 
для решения тех задач, которые вы ставите перед системой "Умная линия"?

Да, действительно, в каждой единице современного оборудования есть определенные средства для обратной связи и элементы интеллектуальности. Но проблема в том, что линии состоят из машин разных производителей, и состыковать все эти программные продукты далеко не тривиальная задача. Свести всё в единое целое как раз одна из задач, которые помогает решить «Умная линия».

К тому моменту, как возникла идея приобретения "Умной линии", на вашем предприятии уже была внедрена система ERP? Эти системы интегрированы между собой?

ERP-систему в том виде, в каком она существует у нас сейчас, мы начали внедрять более пяти лет назад. Но у нее была предшественница - автоматизированная система управления производством (АСУП), которая была создана еще в советские времена и выполняла ряд задач, относящихся сегодня к сфере ЕRP-систем. Мы сохранили производственную базу данных АСУП, которая была транслирована в нынешнюю ЕRP-систему, поэтому можно считать, что система управления ресурсами предприятия у нас существует и непрерывно развивается еще с 1980-х.

На данный момент "Умная линия» с нашей ЕRP-системой напрямую не интегрирована, но эта задача стоит, и мы ясно понимаем, как это сделать. На это не потребуются годы.

В то же время данные системы могут работать и независимо друг от друга. Это тоже дает эффект.

Помимо "Умной линии", вы внедряете систему "Умное рабочее место". Она призвана решать схожие задачи для участка ручного монтажа?

С помощью данной системы мы также хотим повысить эффективность работы на основе более точных и оперативных данных о производственном процессе. Кроме того, система призвана сыграть важную роль в обеспечении полной прослеживаемости - от элемента до конечного изделия. Сейчас мы тестируем "Умное рабочее место", совместно со специалистами Остека адаптируем ее к нашим особенностям. И я должен отметить в качестве преимущества этой системы, что она очень гибкая. Для подобных решений это крайне важно: ручной монтаж - специфическая операция, во многом зависящая от конкретного производства, от применяемых подходов и традиций предприятия. Создать универсальное решение для сбора информации с рабочих мест монтажников и правильной ее обработки не представляется возможным. Поэтому то, как система может адаптироваться и как в этом помогает ее разработчик, становится ключевым фактором успеха.

Хотя еще некоторую работу предстоит выполнить, уже можно с уверенностью сказать, что к нашему производству "Умное рабочее место» адаптировано будет. А далее мы приступим к интеграции этого решения с нашей ERP-системой. В данном случае это важно, потому что каждое отдельное рабочее место - это лишь островок производства, и для решения поставленных задач по сбору информации, управлению и обеспечению прослеживаемости все эти островки должны быть объединены между собой и с общей системой управления производством.

Но "Умное рабочее место» помогает нам еще в одном аспекте. Несколько лет назад мы приняли решение, что монтажники не должны работать по чертежам, выполненным по всем правилам ЕСКД. Во-первых, не все обладают достаточной квалификацией, чтобы их правильно читать, а во-вторых - постоянно изготавливать их копии для рабочих мест не только трудозатратно, но и рискованно: их сложно отслеживать, и есть опасность, что монтажник возьмет в работу устаревший чертеж, в котором не отражены те или иные изменения. Кроме того, некоторые монтажники у нас наносили на чертежи свои пометки, которые позволяли им работать более эффективно, но этой информацией ни с кем не делились - это было их "ноу-хау", что не позволяло использовать эти идеи для улучшения процесса производства в целом.

Поэтому мы стали разрабатывать операционные карты. Они содержат только необходимую для выполнения монтажа информацию и их проще читать. Кроме того, мы мотивировали монтажников делиться теми идеями, которые возникают у них для улучшения процесса, с помощью технологий "бережливого производства", кайдзен-предложений. За свои предложения они получают определенный бонус, а улучшение внедряется для всех, кто выполняет соответствующие операции.

Система "Умное рабочее место" помогает тем, что она позволяет очень легко работать с документацией в электронном виде. Поэтому проблема с учетом операционных карт исчезает, не нужно изготавливать их копии, а вносимые изменения мгновенно отражаются на экранах всех рабочих мест.

Вы упомянули о полной прослеживаемости, а она обычно начинается со склада комплектующих...

В этой области мы в ближайшее время планируем внедрить тоже очень современное решение - «Умный склад". Мы задумали это около двух лет назад и подошли к данной задаче очень основательно: изучили опыт различных предприятий, в том числе из Голландии и Японии, около года формировали Т3, на поиски подрядчика ушло не менее полугода. Сейчас для этого проекта 

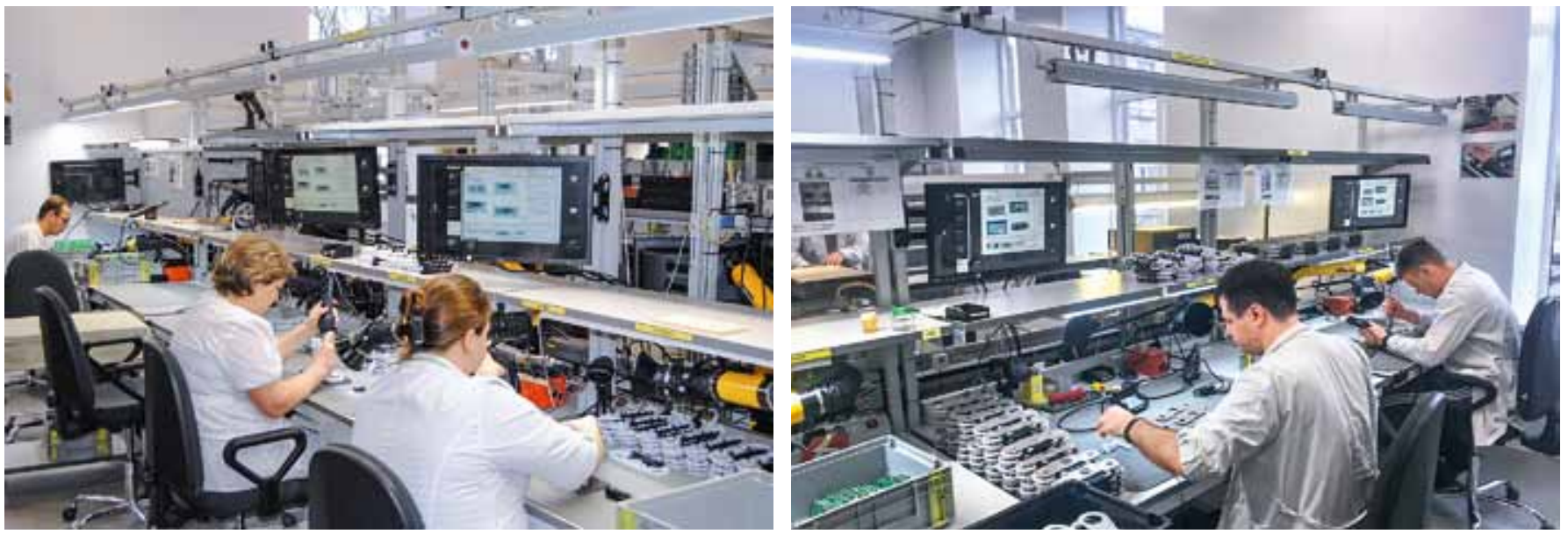

Система "Умное рабочее место" на участке ручного монтажа

уже закуплено оборудование, завершается подготовка помещений. Мы планируем запустить данную систему в середине 2020 года.

Мы остановились на решении российского разработчика - компании "Сенсорлинк-Логистика". Нам очень понравился их подход: открытость и готовность К тому, чтобы учесть все наши особенности и пожелания. Это их выгодно отличает от зарубежных компаний, которые обычно поставляют только готовые решения под ключ. Так, большинство складских систем рассчитано на помещения с высотой потолков 15-20 м. У нас же такой возможности нет: мы используем имеющиеся помещения, которые существенно ниже и плюс к тому расположены на третьем этаже. Кроме того, зарубежные и крупные российские разработчики, как правило, не готовы раскрывать свое ПО, что усложняет стыковку их систем c ERP. А нам такая стыковка необходима.

Специалисты "Сенсорлинк-Логистика» пошли нам навстречу, учли наши пожелания и ограничения и предоставили ПО для выполнения стыковки с ЕRP-системой.

\section{Это будет полностью автоматизированный склад?}

Да.Хранение будет осуществляться в ящиках, расположенных на стеллажах. Поступившие изделия будут расставляться на свои места с помощью робота на основе информации со штрихкодов. Также с помощью штрихкодирования согласно комплектовочной ведомости роботы будут собирать комплектацию под конкретный заказ и выдавать комплектовщику для передачи непосредственно на рабочее место или на комплекс рабочих мест

Комплектовочные ведомости будут готовиться автоматически в ERP-системе на основе плановых задач. И что очень важно, при выдаче комплекта будет автоматически производиться списание комплектующих со склада под конкретный заказ и оформляться поступление на соответствующий участок. Данная информация будет сразу учитываться в бухгалтерской системе.

Благодаря такому автоматизированному учету мы в каждый момент времени будем обладать в том числе полной информацией о незавершенном производстве.

\section{Будет ли реализовано на этом складе сухое хране-} ние?

У нас сухое хранение предусмотрено у линии. Компоненты в обязательном порядке высушиваются перед монтажом - это требование технологии, а чем ближе к линии расположен шкаф сухого хранения, тем лучше.

Здесь будет лишь несколько шкафов, предназначенных для особых случаев, например для длительного хранения особо чувствительных к влажности компонентов.

Тем не менее в той части склада, которая предназначена для хранения покупных комплектующих изделий, будет обеспечиваться необходимый температурный режим. Во второй части, где будут располагаться детали и сборочные единицы собственного производства, особого климатического режима не требуется, и там изделия будут храниться в обычных условиях.

\section{Сухое хранение у линии будет тоже автоматизиро-} ванное?

Да, здесь комплектация уже выдается автоматически в соответствии с плановыми задачами. Это еще одно решение, которое мы внедрили вместе с Группой компаний Остек, продолжая движение по пути постоянного совершенствования производства.

\section{Спасибо за интересный рассказ.}

